\title{
General Psychiatry Cognitive-behavioural therapy for personal recovery of patients with schizophrenia: A systematic review and meta-analysis
}

\author{
Weiliang Wang, ${ }^{1}$ Yuqiu Zhou, ${ }^{1}$ Nannan Chai, ${ }^{2}$ Dongwei Liu ${ }^{1}$
}

To cite: Wang W, Zhou Y, Chai N, et al. Cognitive-behavioural therapy for personal recovery of patients with schizophrenia: A systematic review and metaanalysis. General Psychiatry 2019;32:e100040. doi:10.1136/ gpsych-2018-100040

- Additional material is published online only. To view please visit the journal online (http://dx.doi.org/10.1136/ gpsych-2018-100040).

Received 23 November 2018 Revised 03 July 2019 Accepted 17 July 2019

\section{ABSTRACT}

Background To date, cognitive-behavioural therapy (CBT) trials have primarily focused on clinical recovery; however, personal recovery is actually the fundamental aspect of the recovery process. The aim of this study was to summarise and synthesise the existing evidence regarding the effectiveness of CBT for personal recovery in patients with schizophrenia.

Aim This study aimed to determine the effectiveness of CBT for personal recovery in patients with schizophremMethods A systematic search of the literature in PsycINF0, PubMed, Cochrane (CENTRAL), Embas and Web of Science (SCI) was conducted to identify randon ed controlled trials reporting the impact of $\mathrm{CBT}$ interver ns on personal recovery in patients with estimated effect sizes of the main study utcon calculated to estimate the manitude of effects of CBT on personal covo We al evaluated the CBT's effect size at the rd-of-tre ment an ong-term (follow-up) changes in ne as recovery. Results Twenty ve stua, vere included in the analysis. The effect of on persona covery was 2.27 (95\% Cl 0.10 te 45 ; $\quad \%$; $p=0.04$. post-treatment and the lo term effect was $2.62(95 \% \mathrm{Cl} 0.51$ to 4. $\left.1^{2}=0 \% ; p=0.02\right)$. $D$ ing the post-treatment period, pooled sect size of CBT was $0.01(95 \% \mathrm{Cl}-0.12$ $0.15=33.0 \% \cdot \mathrm{D}>0.05)$ for quality of life $(\mathrm{Q} \mathrm{L})$, 0.6 . $95 \% \mathrm{Cl}^{\circ}, 56$ to $1.130 ; \mathrm{l}^{2}=30.8 \% ; \mathrm{p}<0.01$ ) for psycho ic realth-related QoL, $-1.77(95 \% \mathrm{Cl}-3.29$ to $-0.25 ;=40 \% ; p=0.02$ ) for hopelessness and 1.85 0.69 to $3.01 ; l^{2}=41 \% ; p<0.01$ ) for self-esteem. We also summarised the effects of CBT on QoL (subscale scores not included in the evaluation of the pooled effect size), self-confidence and connectedness, and all results corresponded to positive effects. However, there was insufficient evidence regarding the long-term effects of CBT on personal recovery.

Conclusions CBT is an effective therapy with meaningful clinical effect sizes on personal recovery and some aspects of personal recovery of schizophrenia after treatment. However, the effect is relatively immediate and rapidly decreases as time progresses. Therefore, in the future, more studies should focus on the mechanism of CBT for personal recovery and the factors that influence the long-term effects of CBT.

Trial registration number CRD42018085643.

\section{INTRODUCTION}

Schizophrenia, a vere men 1 illness, affects more thar 1 millio peopl worldwide. ${ }^{1}$ The persist negrive s) oms and cognitive impar ent ssociated with schizophrenia b é led ts class cation among the top 25 ding cau disability worldwide and the to 1 leading causes of reduced years lived with ability in 2013. ${ }^{2}$ The WHO's Mental Health Artion Plan 2013-2020 highlights the aps required to provide appropriate services people with schizophrenia. ${ }^{3}$ Cognitive-behavioural therapy (CBT) is the primarily recommended psychological treatment for schizophrenia according to major guidelines. ${ }^{45}$ Abundant studies have proven that the effects of CBT on reducing positive symptoms, ${ }^{6}$ improving negative symptoms, ${ }^{7}$ conferring functional improvement, ${ }^{8}$ reducing the time of relapse ${ }^{9}$ and reducing suicidal ideation ${ }^{10}$ in patients with schizophrenia are significant. However, the remission of clinical symptoms does not meet the criterion for rehabilitation, and patient organisations have emphasised that recovery can occur even when psychotic symptoms are persistent. ${ }^{11}$ Recovery is an ongoing, complex and multidimensional process. According to different perspectives, schizophrenia recovery can be classified as clinical and personal. ${ }^{12}$ In the treatment of patients with schizophrenia, the primary goal traditionally is the clinical recovery. Clinical recovery includes remission of symptoms and functional improvement, which is the premise of other non-pharmacological treatments and rehabilitations. The relationship between the clinical and personal recovery is somewhat correlated, and both should be considered when monitoring the treatments and outcomes of patients with schizophrenia. ${ }^{13}$ The term 'personal recovery', which based on the perspective of individuals who have 
experienced mental illness, ${ }^{14}$ has been widely used in the literature to describe the patient-based definition of recovery. ${ }^{15}$ The most frequently cited patient-based definition is 'the development of new meaning and purpose in one's life as one grows beyond the catastrophic effects of mental illness. ${ }^{16}$

Personal recovery varies from person to person, and it is difficult to define common characteristics. Different researchers also have their own definitions of personal recovery. Andresen et $a l^{17}$ concluded that personal recovery included four key points: finding hope; re-establishing identity; finding meaning in life; and taking responsibility for recovery. Leamy et $a l^{18}$ posited that the categories of personal recovery encompass connectedness, hope, identity, meaning and empowerment. Based on a cluster analysis of self-reported personal recovery-related variables, Rossi $e t a l^{19}$ identified resilience, self-esteem, coping strategies, stigma and personal strength. Furthermore, quality of life (QoL), ${ }^{20}{ }^{21}$ taking control of one's life, ${ }^{22}{ }^{23}$ personal confidence and reliance on others ${ }^{24}$ have been found to be important components of personal recovery.

According to a review of the abundant literature on personal recovery, which have most consistently identified connectedness, hope and empowerment as relevant categories, ${ }^{13}$ and discussions by our research team, we decided to use the CHIME personal recovery model defined by Leamy et $a l^{18}$ : Connectedness-Hope-Io tity-Meaning-Empowerment. In addition, this mode consistent with the context of recovery defined by th WHO. ${ }^{25}$ Based on the progress of pharmaco ment of acute psychiatric symptoms of nizop enia, QoL measurement has become an

cator for evaluating clinical outcon in ents with schizophrenia. ${ }^{26}$ Furthermore, $\mathrm{O}$ is one of he most commonly used outcome asses dents To better address the concept of personal reco ty, we havo so considered QoL in the assessment of rsonal recovery.

The concept of recov is my dimensional; why, then, should personal recovery prim y focus? Personal recovery pertains tient bili to live a favourable, dignified and eaning ul life. s the core element of recovery from he $\mathrm{p}$ arpective, and it is the ultimate aim of mo illness treatment. Moreover, some components of pen nal recovery, such as hope, are the foundations and preomditions of treatment and other outcomes. ${ }^{27}$ In addition, Jahn $e t a l \mathrm{~s}^{28}$ finding suggests that personal recovery is a protective factor against suicidal ideation in individuals with schizophrenia. However, existing knowledge about the role of CBT in personal recovery is highly limited, and the current meta-analyses focused only on clinical outcomes; ${ }^{29}{ }^{30}$ therefore, the aim of this study was to determine the effectiveness of CBT for personal recovery in patients with schizophrenia. This research has been registered at PROSPERO (CRD: 42018085643), and the study protocol can be obtained via the following website: https://www.crd.york.ac.uk/ PROSPERO/\#recordDetails.

\section{METHODS}

The Preferred Reporting Items for Systematic Reviews and Meta-Analyses statement ${ }^{31}$ were followed in all steps of this research.

\section{Search strategy}

Five electronic databases, PsycINFO, PubMed, the Cochrane Library (CENTRAL), Embase and Web of Science (SCI),were searched for relevant papers published before 31 December 2018 with the following search terms: ('psychosis' OR 'psychotic' OR 'schizophrenia' OR 'schizoaffective disorder') AND ('cognitive therapy' OR 'cognitive behavior* therapy' OR 'cognitive behaviour* therapy' OR ' $C$ AND ('random' OR 'randomized control trial' 'clinic trial' OR 'trial'). Manual searches were also erformed y reviewing the reference lists of rel $/ \mathrm{d}$ pa $\mathrm{rs}$. Two reviewers (WW and NC) independ atly screen th search results by reviewing titles a absty ats. The ull texts of relevant articles screen $d$ in rous st were downloaded for further scr ning. If e sa data were reported in more the on ublicatio only the paper with the more complete data was included. Any disagreement was set discussio yith the third author (ZY). (See the f w chart of the study, figure 1.)

In usion and xclusion criteria

The of personal recovery in our study included components: connectedness, hope,identity,meanng,onpowerment; and QoL. Studies that fulfilled the following criteria were included: (1) randomised controlled trials; (2) publications with full texts written in English; (3) participants diagnosed with schizophrenia or schizophrenia spectrum disorder based on the International Classification of Diseases-Tenth Revision or Diagnostic and Statistical Manual of Mental Disorders-Fourth/Fifth Edition; (4) the use of a valid measure to assess personal recovery (CHIME and QoL); and (5) a psychological intervention of CBT or a CBT-modified programme, but not in combination with other psychological interventions.

The exclusion criteria were as follows: (1) no relevant data available for further analysis; (2) article types other than randomised controlled trials (RCT), such as comments, letters and reviews; and (3) other cognitive therapies, such as cognitive training, cognitivebehavioural social skills training, cognitive remediation therapy or cognitive enhancement therapy.

\section{Data extraction}

Data extraction was performed by two independent reviewers (WW and NC) who used a specific worksheet designed before the literature search to minimise errors in data extraction. Data extraction was conducted using the full-text versions of the RCTs. The data regarding basic characteristics and outcome measures, including study identity (first author, publication year and country); study design (randomisation, concealment of allocation, 
Records identified through database searching $(\mathrm{N}=4146)$ : PubMed $(\mathrm{n}=476)$, Embase $(n=642)$, Cochrane $(n=859)$, Web of Science $(n=1046)$, PsycINFO $(n=1123)$.

Duplicated records $(\mathbf{n}=\mathbf{1 6 5 3})$

Records screened by title or abstract $(\mathbf{n}=\mathbf{2 4 9 3})$

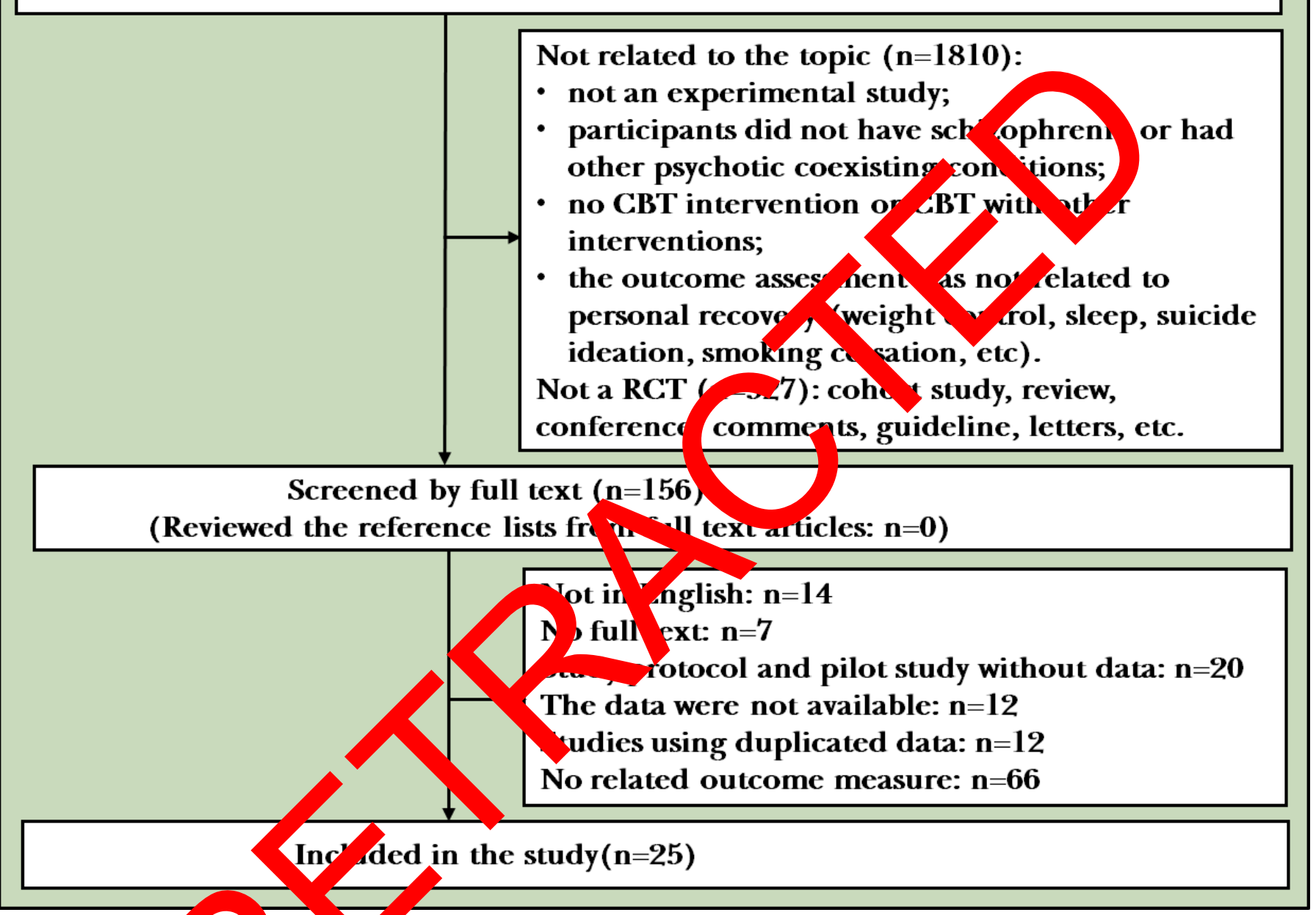

Figure 1 The fl chart f searo a study selection. CBT, cognitive-behavioural therapy; RCT, randomised controlled trial.

blinding); patie number of study participants, mean age); intervention haracteristics (treatment protocol, length of treatment, Aumber of sessions and type of comparisons); and all relevant outcomes (types of outcome measures, instruments and follow-up periods) were extracted from all included studies.

\section{Quality assessment}

The quality of the RCTs enrolled in our study was assessed using the Cochrane Collaboration's tool for determining the risk of bias in randomised trials. ${ }^{32}$ According to the Cochrane assessment tool, the relevant information was extracted from each study, and the study was rated as 'high risk', 'low risk' or 'unclear risk'. Disagreements were resolved by consensus.

\section{Statistical analysis}

All the pooled effect size was performed by RevMan V.5.0. The $\mathrm{I}^{2}$ statistic was used to evaluate the heterogeneity of the studies. Sensitivity analysis and subgroup analysis were performed to deal with heterogeneity. Forest plots were also drawn to visualise the extent of heterogeneity across studies. Publication bias was evaluated using Egger's test by Stata (V.14.2). Hedge's g was used to determine the effect size of continuous outcomes. Considering the heterogeneity of the personal recovery outcome measures, we summarised the pooled results narratively with descriptive statistics and textual descriptions. A two-tailed $p<0.05$ was considered statistically significant. A power analysis to examine the reliability of the pooled result was performed with GPower V.3.1. 
The Grading of Recommendations Assessment, Development and Evaluation (GRADE) approach was performed to assess confidence of evidence (CoE) for each comparison. CoE of outcomes was rated based on study design, risk of bias, inconsistency of results, indirectness of evidence, imprecision and publication bias. We used the GRADEpro Guideline Development Tool to assess the CoE of the critical outcomes.

\section{RESULTS}

\section{Study selection}

A total of 4146 articles were retrieved from the electronic databases. After duplicates were discarded, 2493 remaining studies were screened. According to the inclusion and exclusion criteria, approximately 2337 records were removed after screening to determine whether the article titles and abstracts were relevant to the topic of the review. The full texts of the remaining 156 studies were reviewed. We manually searched by reviewing the reference lists from the full-text articles, and none of the references were related to the topic. Finally, 131 studies did not meet the inclusion criteria, leaving 25 studies for inclusion in this review. The details of the search process are shown in figure 1.

\section{Study characteristics}

All the participants included in the 25 studies $^{33-57}$ we diagnosed with schizophrenia or schizoaffecting dison ders; the patients in seven studies were re aite from hospitals, and the patients in the other studi were recruited from the community or mer al h $1+$ centros. The intervention treatment proy ed in $\mathrm{n} t$ of the studies was CBT; 1 of the 25 di ${ }^{44}$ used co vitivebehavioural oriented services (CBOS) the intervention group's treatment, $b / \mathrm{CBOS}$ is so considered as CBT on the basis of core heory and implementation. All the compar o oups received treatment as usual, suppor roup stand d care, standard treatment (ST) stan ard st $\mathrm{t}$, befriending, waitlisting or pa nt ps heeducation therapy, except in two studies ${ }^{37}$ compared CBT versus CBT plus clozapine and $\mathrm{CB}$ - versus $\mathrm{CBT}$ plus thioridazine. Three studies $^{53} 5457$ repor directly the personal recovery using the Questionnaire about the Process of Recovery (QPR) scale, 11 studies $3335374043505153-56$ reported QoL; 5 studies ${ }^{343645}$ reported hope as an outcome of personal recovery; self-esteem, a core element of a better and more meaningful life for psychiatry patients, was measured in 11 studies $^{34} 39414245-495257$; 3 studies $^{39} 4455$ reported relationships with others as an outcome; and 1 study $^{39}$ reported self-confidence as an outcome of personal recovery. No studies reported empowerment as an outcome. Twelve of the studies reported sufficient follow-up data to evaluate the long-term effect of CBT in schizophrenia (table 1).

\section{Quality of the studies}

The risk of bias for each study is available in the online supplementary material 1. Eleven ${ }^{353638394248505153-55}$ of the 25 studies were universally assessed as having a low risk of bias across all domains. Fifteen trials ${ }^{3536383942444548505153-57}$ employed adequate methods of sequence generation, 10 trials 31333437404346474952 were not clear. In addition, the risk of bias due to inadequate allocation concealment was unclear in seven trials, ${ }^{34374043454652}$ and four 33414749 trials did not include allocation concealment. Lack of blinding of the assessors led to a high risk of bias for some outcomes in four studies, ${ }^{414447}$ and an unclear risk in four studies. ${ }^{33} 374352$ A high risk of bias due to lack of participants or staff blinding w d in two studies ${ }^{33} 47$ and was unclear in three sty es. $^{3745}$ There was a high risk of bias due to incomple outcomed ta for two of the included trials; ${ }^{4345}$ one ial $^{44}$ not re prt all outcomes.

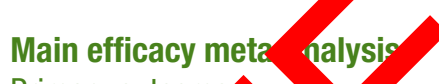

Primary outcome

Three stud $s 34$ port the effect of CBT for personal $c \mathrm{Co}$ ry measu by QPR. The random effects meta-analysis ylo ed a summary effect size of $2.27(95 \%$ CI $4.45 ; \mathrm{I}^{2}=$; $\mathrm{p}=0.04$, power=0.61). Egger's test dicated that there was no publication bias $(p=0.96$, $\% \mathrm{CI}-18$. to 17.96). The long-term effect of CBT was $\mathrm{m}$ sured in hese three studies and the pooled effect size was $\%$ CI 0.51 to $4.47 ; \mathrm{I}^{2}=0 \% ; \mathrm{p}=0.02$, power $=0.13$ )

cioure 2).

Secondary outcomes

Effect size of QoL

Nine studies $33 \quad 37404351$ 53-56 reported QoL total scores based on questionnaires. The random effects meta-analysis yielded a summary effect size of 0.01 (95\% CI -0.12 to $\left.0.15 ; \mathrm{I}^{2}=33.0 \% ; \mathrm{p}>0.05\right)$ and a power analysis result of 0.97 (figure 2). Egger's test indicated that there was no publication bias $(\mathrm{p}=0.54,95 \% \mathrm{CI}-1.40$ to 2.48$)$. The participants in three studies ${ }^{40454}$ were recruited from hospitals, and the participants in six studies were recruited from outside the hospital. Both the inpatient and outpatient subgroups yielded a small and non-significant effect of schizophrenia on QoL (online supplementary material 1). Seven studies ${ }^{33} 3751$ 53-56 reported CBT follow-up for QoL in schizophrenia, and the pooled effect size was 0.06 (95\% CI -0.03 to $0.15 ; \mathrm{I}^{2}=15 \%$; $\left.\mathrm{p}>0.05\right)$ with a small power of 0.19 . The follow-up times differed among the studies (1 month; ${ }^{33} 3$ months; ${ }^{3755} 566$ months and above $^{515354}$ ). We evaluated the effect sizes using Cohen's $\mathrm{d}$, and the pooled effect sizes were 0.36 ( 1 month), 0.08 $\left(95 \% \mathrm{CI}-0.31\right.$ to $0.47 ; \mathrm{I}^{2}=57.0 \% ; \mathrm{p}>0.05$, power $\left.=0.87\right) \quad(3$ months) and 0.04 (95\% CI -0.00 to $0.09 ; \mathrm{I}^{2}=0 \% ; \mathrm{p}=0.05$, power=0.11) (6 months and above) respectively. After performing the sensitivity analyses, no substantial change in the new pooled effect size was observed.

Four studies ${ }^{35-40}$ reported the psychosocial well-being of the patients, as measured by the Warwick-Edinburgh Mental Well-Being Scale (WEMWBS), a subscale of the 


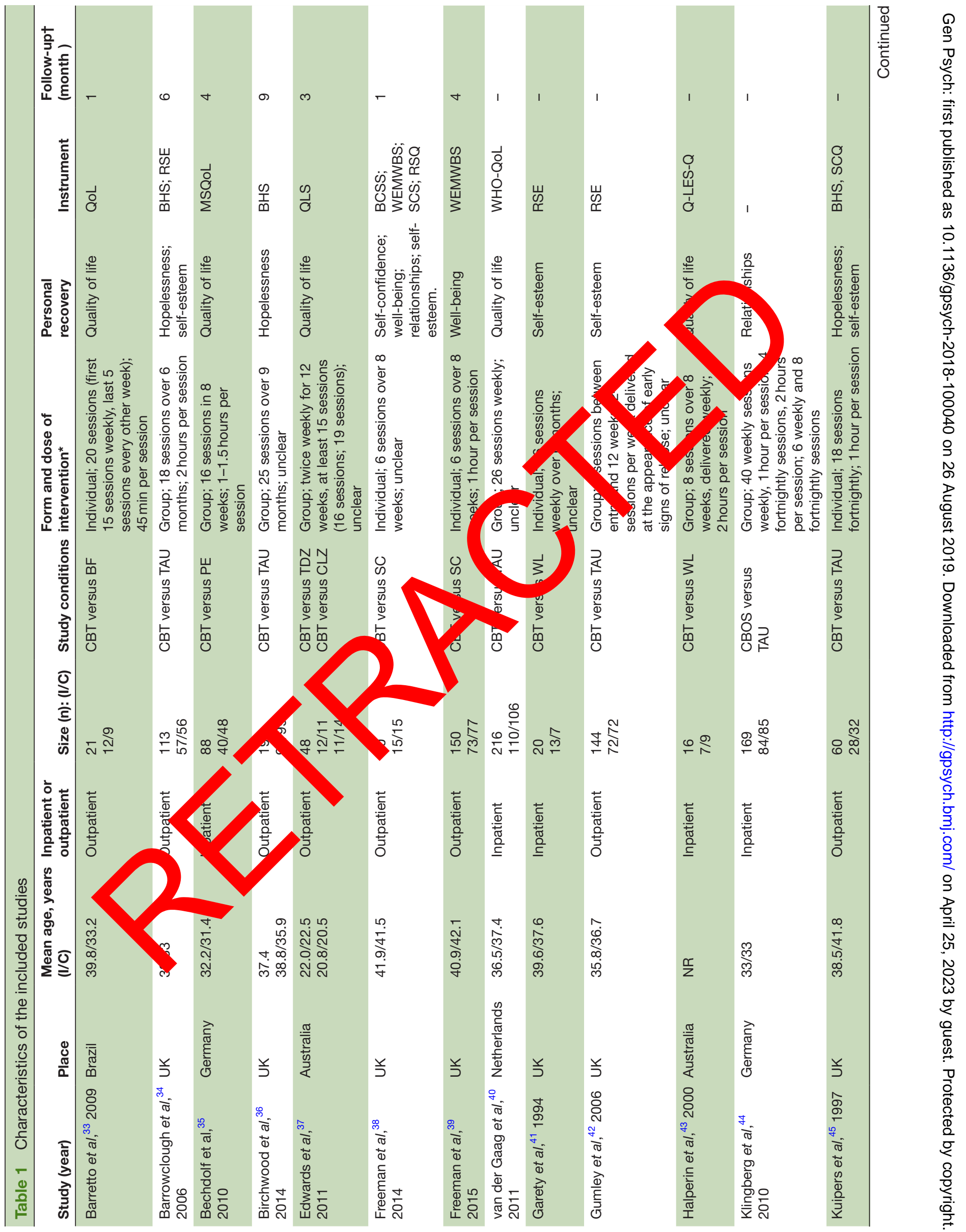




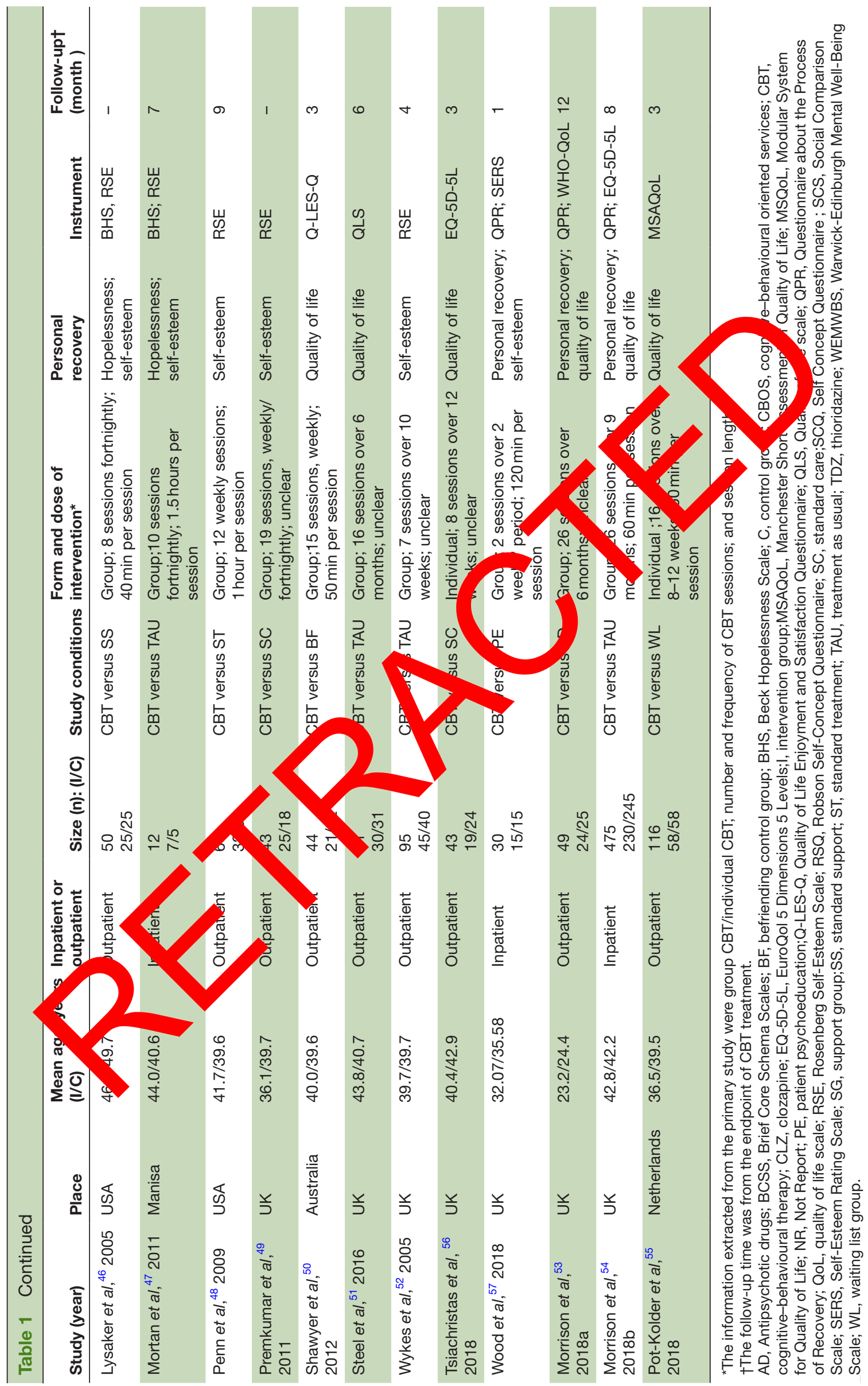




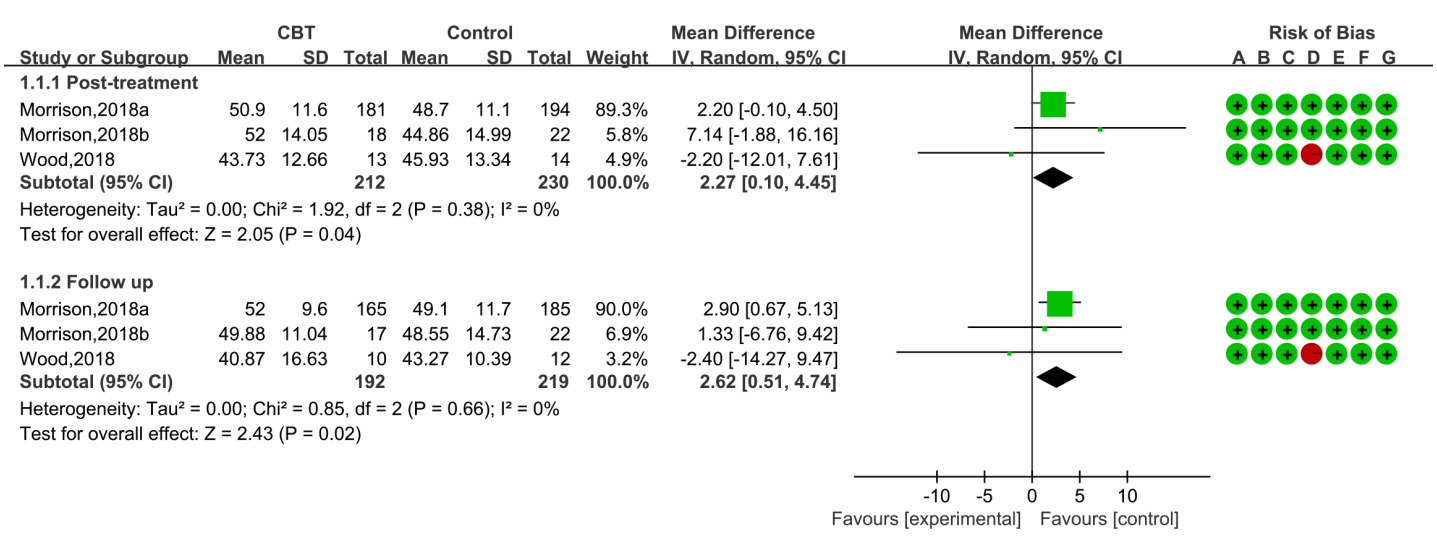

Risk of bias legend

(A) Random sequence generation (selection bias)

(B) Allocation concealment (selection bias)

(C) Blinding of participants and personnel (performance bias)

(D) Blinding of outcome assessment (detection bias)

(E) Incomplete outcome data (attrition bias)

(F) Selective reporting (reporting bias)

(G) Other bias

Figure 2 Forest plot of the effect of cognitive-behavioural therapy (CBT) on personal covery

Modular System for Quality of Life (MSQoL) scale and the WHO-QoL psychological well-being subscale. Because of the high heterogeneity $\left(\mathrm{I}^{2}=91.0 \%, \mathrm{p}<0.001\right)$, it was not appropriate to directly combine the effect sizes; thus, a descriptive analysis was performed. Two studies investigated psychological health with WEMWBS; ${ }^{38}{ }^{39}$ the pooled effect size was 0.64 (95\% CI 0.06 to $\left.1.13 ; \mathrm{I}^{2}=30.8 \% ; \mathrm{p}<0.01\right)$ and the long-term effect size was 0.38 (95\% CI $0.0 \%$ $\left.0.69 ; \mathrm{I}^{2}=0.00 \% ; \mathrm{p}<0.01\right)$. In a restrictive and high-qua RCT, Bechdolf $e t a l^{35}$ investigated the effect of CBT o patients' psychosocial well-being using a sub an the MSQoL. The results showed that the $\mathrm{CB}^{\prime}$ prog mme improved the patients' psychological hea -rela with a small effect size (Cohen's $d=9,3$ ). $M$ cover, the long-term effect of CBT was signif t accords to data collected 4 months after treatm it an had a muderate effect size (Cohen's d=0.37) an der Gaa t $a t^{40}$ used the WHO-QoL psychological ell-being subsc to reflect the psychological heal of pat its with schizophrenia. The results showed that sonific tly improved the patients' QoL, wi a rge ect si at the end of treatment (Cohen's

Shawyer et 50 in $20 L$ using two subscales from the Quality Ufe Enjoyment and Satisfaction Questionnaire: Subjectr Feelings and General Activities. In addition, the endpon effect sizes of the two subscales corresponded to Cohen's d values of 0.02 and 0.43 , and the follow-up effect sizes were -0.48 and 0.14 respectively. The study also evaluated the life satisfaction and life enjoyment with special items, and the Cohen's d values were 0.37 and 0.08 with long-term effect sizes of 0.20 and -0.19 respectively. Bechdolf et $a l^{35}$ reported subjective QoL measured with the MSQoL-seven subscale scores at post-treatment and at a 6-month follow-up. The effect sizes of the seven subscales (endpoint, follow-up) were as follows: Physical Health $(0.11,0.21)$, Vitality $(0.01,0.36)$, Psychosocial QoL $(0.03,0.37)$, Affective QoL $(0.17,0.27)$, Material QoL $(0.03,0.12)$, Spare Time QoL $(0.30,0.32)$ and Gener QoL $\left(0.0-0.2^{\circ}\right.$. All changes in the effect sizes ove am vere posis

\section{Effer of hope}

Cotal of five studies $343645-47$ investigated the hopelessss levels of patients with schizophrenia using the Beck A pelessnes Scale (BHS), for which higher scores indicato rover levels. Egger's test showed that no publiation blas existed ( $p=0.72,95 \%$ CI -5.65 to 7.23$)$. The na int pooled effect size of the five studies was positive, with an effect size of $-1.77\left(95 \% \mathrm{CI}-3.29\right.$ to $-0.25 ; \mathrm{I}^{2}=40 \%$; $\mathrm{p}=0.02$, power $=0.89$ ) (figure 3 ). Regarding the long-term effect of CBT, three studies ${ }^{34} 47$ reported follow-up data for over 6 months after the treatment. The results showed that the effect of CBT on improving hope among patients with schizophrenia was uncertain $(-0.38,95 \%$ CI -2.78 to $\left.2.02 ; \mathrm{I}^{2}=56 \% ; \mathrm{p}>0.05\right)$, and the three studies only yielded a power of 0.42 . Sensitivity analyses were conducted and after eliminating the studies, no substantial change in the new pooled effect size was observed (figure 4).

\section{Effect size of identity (self-esteem and self-confidence)}

A total of eleven studies $3439414245-495257$ reported self-esteem. The total sample size of these eleven studies was 584 , and the pooled effect size was 1.85 (95\% CI 0.69 to $3.01 ; \mathrm{I}^{2}=41 \% ; \mathrm{p}<0.01$, power $=0.98$ ) (figure 5 ). The result of Egger's test showed that there was no publication bias ( $p=0.20,95 \%$ CI -3.92 to 0.94$)$. For the long-term effect size of CBT, six 343942474857 of the ten studies completed a follow-up evaluation and the effect size was -1.21 $\left(95 \%\right.$ CI -2.45 to $0.04 ; \mathrm{I}^{2}=12 \%$; $\mathrm{p}>0.05$, power $\left.=0.37\right)$. Two $^{39} 57$ of those studies reported results 1 month after the end of treatment, which showed an uncertain effect of CBT $\left(3.61,95 \%\right.$ CI -13.89 to $21.11 ; \mathrm{I}^{2}=28 \%$; $\mathrm{p}>0.05$, power=0.11) and the statistical power was 0.11 . For the other four studies, the follow-up time was over 6 months. Therefore, we combined the follow-up data from these four studies and it revealed a negative long-term effect, 


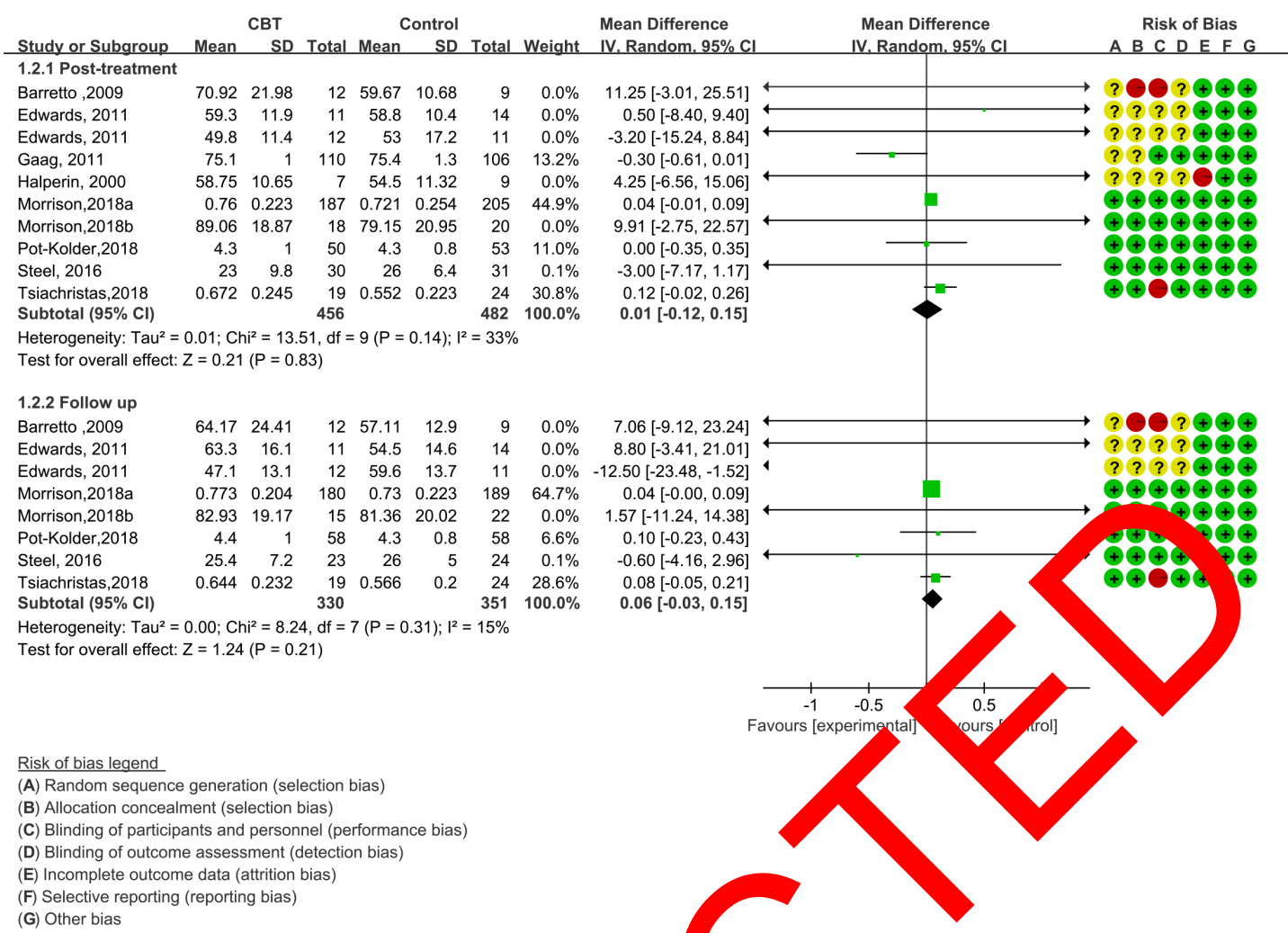

Figure 3 Forest plot of the effect of cognitive-behavioural therapy CBT) on qu ity of life (QoL).

with an effect size of $-1.23\left(95 \%\right.$ CI -2.52 to $0.06 ; \mathrm{I}^{2}=2$ to Con do 0.40 , and the long-term effect size was $\mathrm{p}>0.05$ ) and a power of 0.49 .

One study $^{39}$ assessed the patients' self-confideno using the Brief Core Schema Scales (BCSS The BCSS is designed to assess negative and positi belief a about oneself and others. The endpoint effact $Q$ posm beliefs corresponded to Cohen's d 1.14, b the longterm effect size was only 0.20 at 1 th after to tment. The endpoint effect size of negaruve be fs corresponded

\section{Connectedness}

The Social Comparison Scale is used to assess the patient's relationship with others, and higher scores indicate a more positive view of oneself in relation to others. ${ }^{39}$ The effect sizes were 0.79 and 0.33 at the endpoint and follow-up respectively. Klingberg et $a l^{44}$ investigated the

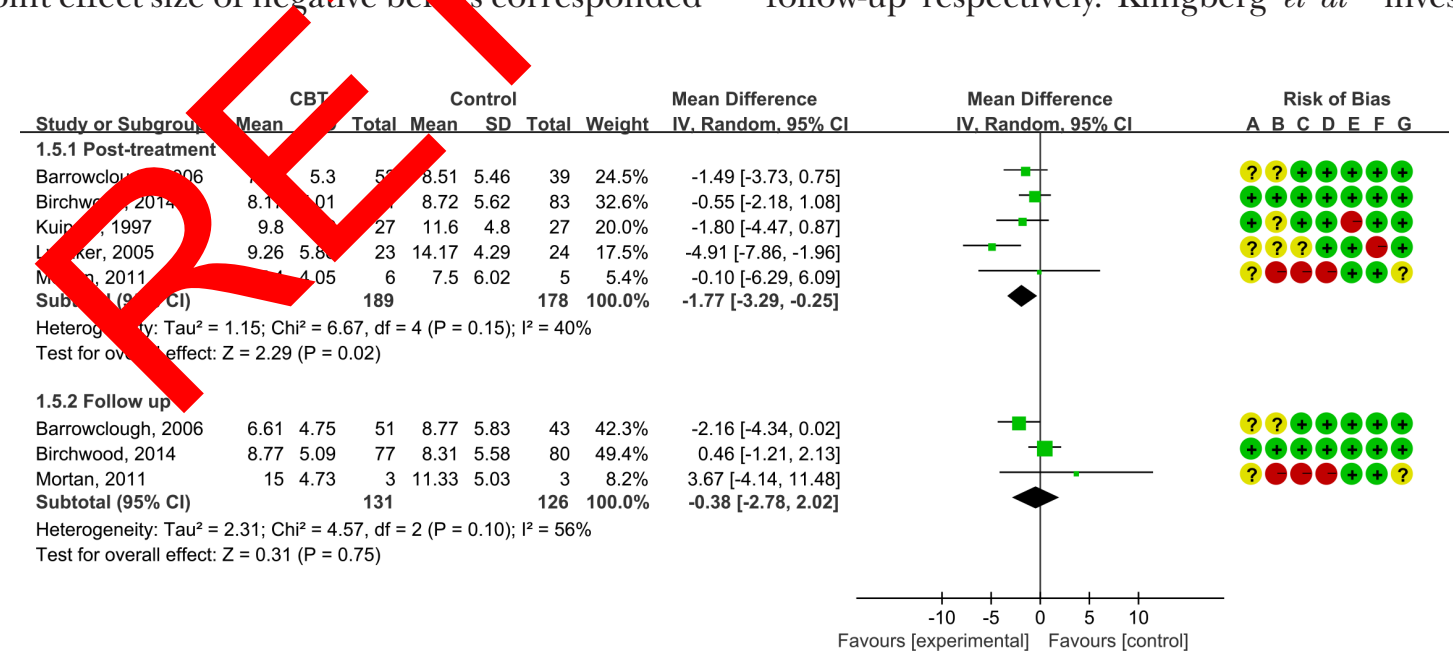

Risk of bias legend

(A) Random sequence generation (selection bias)

(B) Allocation concealment (selection bias)

(C) Blinding of participants and personnel (performance bias)

(D) Blinding of outcome assessment (detection bias)

(E) Incomplete outcome data (attrition bias)

(F) Selective reporting (reporting bias)

(G) Other bias

Figure 4 Forest plot of the effect of cognitive-behavioural therapy (CBT) on hopelessness. 


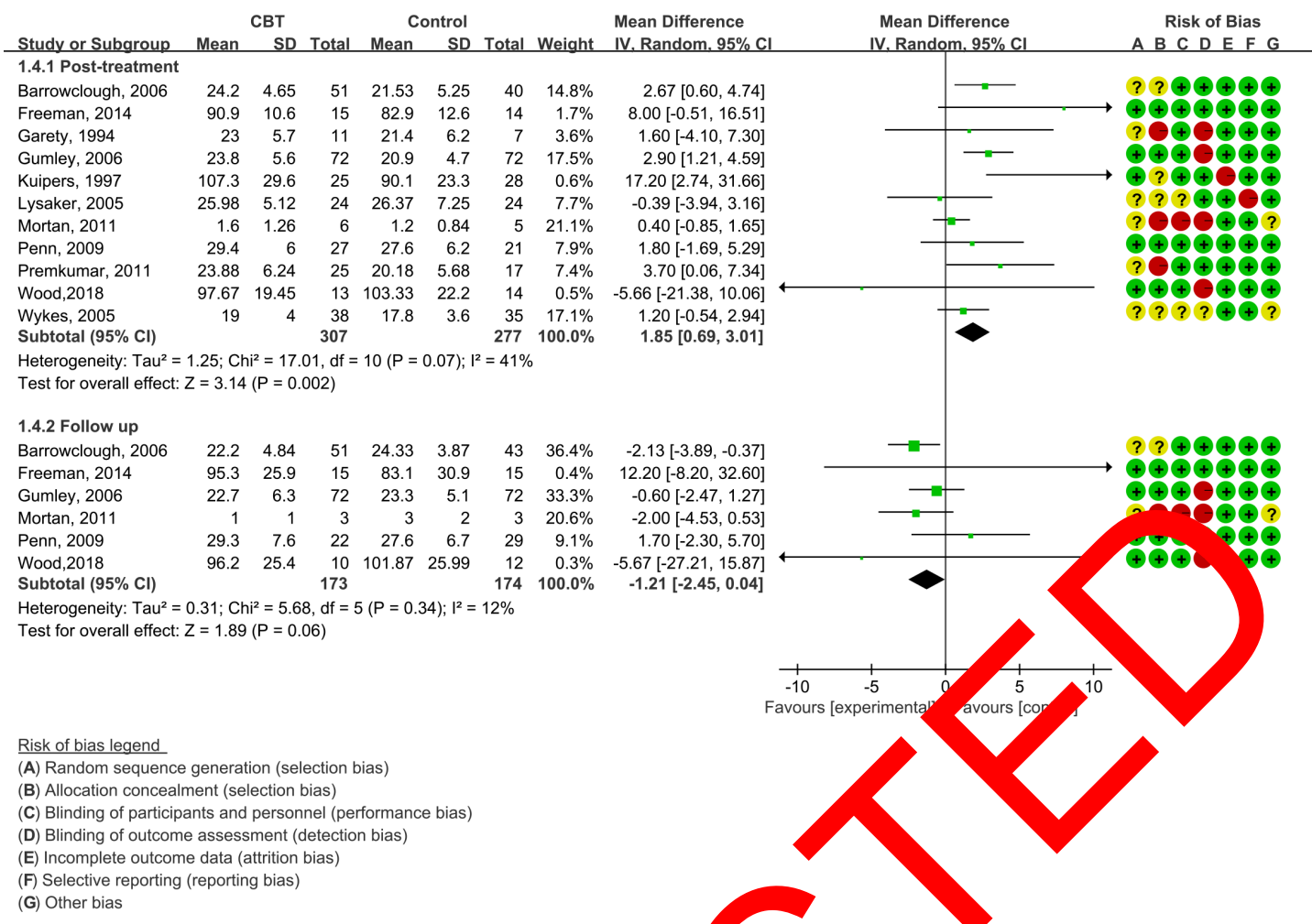

Figure 5 Forest plot of the effect of cognitive-behavioural therapy $\mathrm{CBT}$ ) on self-esteem.

effect on social connections of CBT in schizophrenia by the percentage of connections with relatives CBT treatment, and the result showed significan more improvement than deterioration regarding socia contacts in the CBT group, with 15 of 61 pa cnts xhibiting positive changes after CBT compare with 1 of 60 patients in the control group.

Figure 6 shows the trend of th effect CBT on personal recovery over time from end of thent,

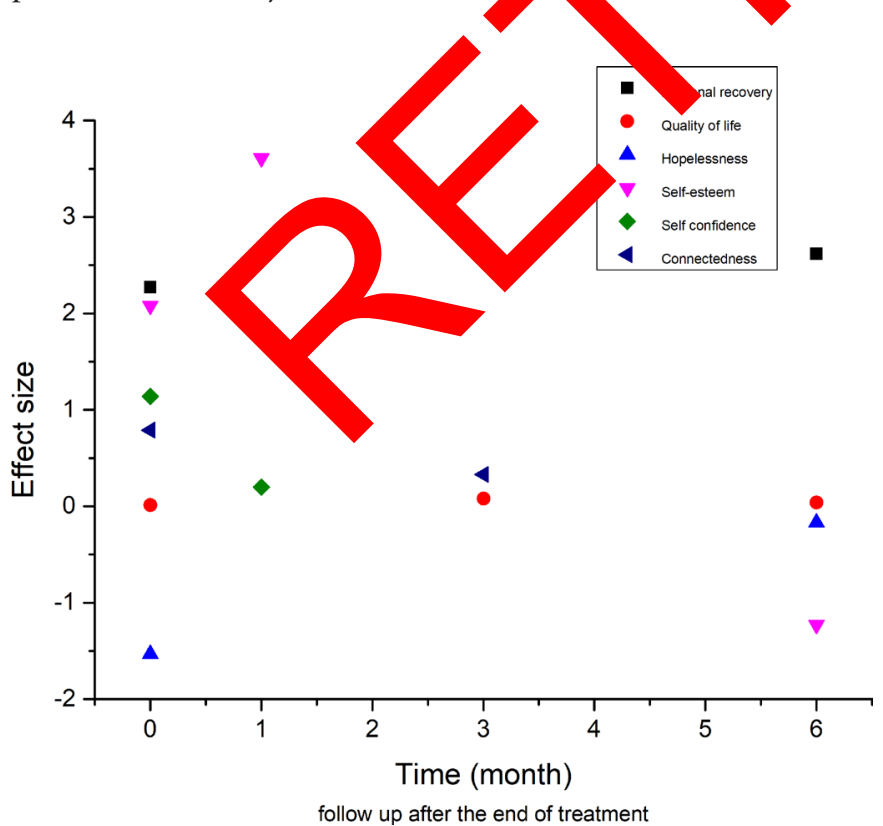

Figure 6 The change in effect size over the followup period. Zero on the $\mathrm{x}$-axis indicates the endpoint of treatment.

\section{DISCUSSION}

Main findings

There has recently been growing attention surrounding the effects of CBT on personal recovery in patients with schizophrenia. The present review examined the efficacy of CBT across 25 randomised clinical trials that included multiple outcomes of personal recovery over different periods of follow-up. Both the post-treatment and the follow-up effect of CBT on personal recovery measured by QPR were positive and significant, which means that CBT can indeed change the patient's recovery process to some extent. However, due to the limited number of studies, the small sample size and low statistical power, the evidence is not sufficient. We also tested the effect of CBT on the specific components of personal recovery. At post-treatment and during the follow-up period, the effect of CBT on QoL in patients with schizophrenia was uncertain for both pooled groups and subgroups, with $p$ values $>0.05$ and powers $<80 \%$. Thus, a conclusion cannot be drawn as to whether CBT is beneficial for patients' QoL due to the limited number of studies, the small sample sizes and the fair quality of the included controlled trials. Additional sufficient and conclusive evidence is needed in the future. 


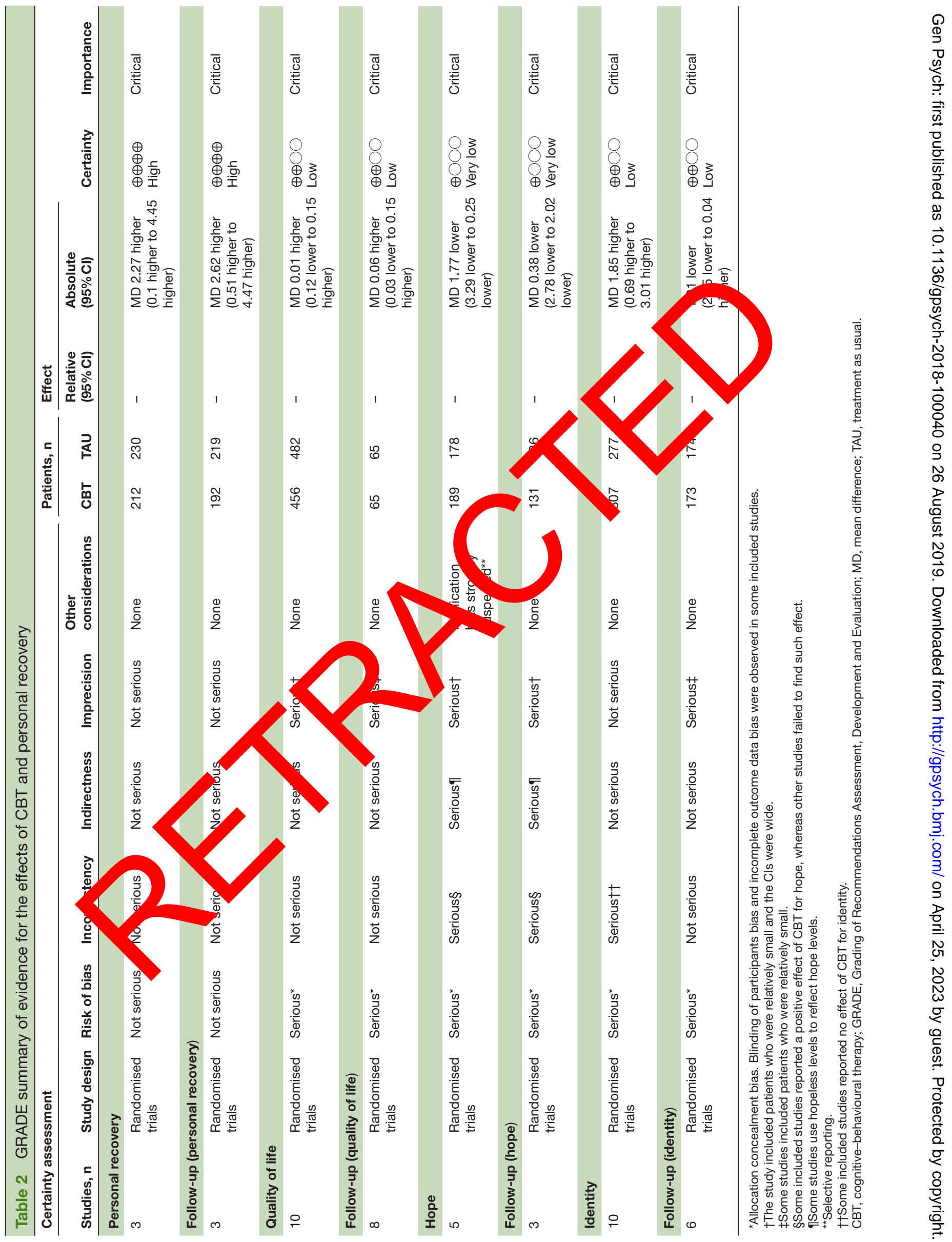


However, for psychological well-being, which is an important component of QoL, the pooled endpoint effect size was significantly large $(>0.6)$, although the long-term effect size decreased to a moderate level. The Subjective Feelings (how much of the time participants feel positive) and General Activities (degree of satisfaction with general activities of life) of patients also showed improvement at post-treatment but decreased at longterm follow-up times. Although this change in effect size with time is in contrary to the trend reported by Bechdolf et $a l,{ }^{35}$ we still believe that CBT is a useful intervention for improving QoL other than psychological health-related QoL in patients with schizophrenia. However, the effect of CBT on QoL in schizophrenia and whether the longterm effect is better or worse than the endpoint should be explored in the future.

The effect of CBT on hope and self-esteem is obvious and positive at post-treatment; however, the long-term effect (over 6 months) is markedly decreased. The self-confidence and relationships of patients with schizophrenia improved little in the CBT group compared with the ST group, and the long-term effect of CBT was the same for hope and self-esteem. These data indicate that the effect of CBT on personal recovery is only sustained for a short time; as time progresses after treatment, the personal recovery of the patients reverts back to the original level. Most studies have only focused on the immediate effects of targeting cognitions about the self have not tried to determine which specific intervent techniques may change the underlying mechanism. ${ }^{39} \mathrm{~V}$ believe that the personal recovery of patien a long-term effort, whether in or out of th nospit, and to maximise the effectiveness of CBT, mor effor be dedicated to continuing CBT inte entio, at specific time points when its effects are $d$ eased ano determining which factors influence

None of these studies rep ted the en $\mathrm{CBT}$ on meaning and empowerp nt in patients vith schizophrenia. Empowermen nclud participating in society in terms of access to em ather ent valued resources rons inte ersonal characteristics, empowern al als means ing control over one's life and the ro very efforts to achieve greater control and selt- acy. There are also some scales available for measurin empowerment, especially among patients with psychods. ${ }^{58}$ Unfortunately, none of the studies included in our research used the empowerment scale as a measure of personal recovery. In the CHIME personal recovery model, meaning is not reported directly, and to the best of our knowledge, there is no specially designed scale for meaning measurement; however, the schizophrenia hope scale designed by Choe $^{59}$ examines positive expectations for the future, confidence in life and the future, and meaning in life, which may help to reflect meaning as an aspect of personal recovery in patients with schizophrenia. Meaning and empowerment can reflect personal recovery to a large extent, and future studies should be designed to verify the effectiveness of
CBT on these components of personal recovery. Moreover, such studies would support the implementation of instruments to measure personal recovery as an outcome.

In the present study, even when strict inclusion criteria were applied to minimise the heterogeneity of the meta-analysis, there was still moderate or even large heterogeneity in some of the outcome analyses. Because of the small number of studies in the high heterogeneity group, the sensitivity analyses and the subgroup analysis were unable to compensate for the heterogeneity; therefore, instead of reporting the results of the meta-analysis, we reported the data as descriptive statistics. Additionally, the outcomes in our study are the best defined main measures for personal recove spite the moderate heterogeneity of some anal es. The niformity among estimates of the effect was narkable $g$ en the unavoidable differences in jerven ans ass iated with the different individual crsonnel du ver the behavioural interventions. In dition e found o statistical evidence of publication ias, ctore sy factors are unlikely to have affect

Some tho esults wer ot statistically significant, with $p$ values $>0.05$. Wwever, the absence of statistical significa hould net be interpreted as evidence that an ect is absent. We performed a power analysis to test the liability of te negative result, and the statistical power w. low or ry low. According to the significance test $(Z=M$, the effect size $(M)$ is the important factor at determines the $p$ value, and the factors that control the power are the same as those that control the significance $^{60}$ (Chapter 29). Therefore, additional higher power studies with restrictive designs and sufficient sample sizes are needed in the future to confirm the effectiveness of CBT on personal recovery in schizophrenia.

\section{Limitations}

There are several limitations of this review. First, some subgroup analyses were not performed due to the limited number of studies. We found that the frequency and number of CBT sessions varied among studies. We initially planned to perform a subgroup analysis according to session design to determine which CBT design corresponds to the best outcome; however, because of the limited number of studies, this subgroup analysis was inappropriate. Therefore, we did not perform this analysis, although this issue could be discussed in future studies aimed at other recovery outcomes. Second, we could not perform a meta-analysis of some outcomes, thus the findings of the effects of CBT are less conclusive and valid. Third, we could not consider all aspects of personal recovery due to the absence of various measures in primary studies. The hope level was represented by the BHS score, which may not be ideal as there is a special hope scale designed for patients with schizophrenia. ${ }^{59}$ Fourth, this review included randomised controlled trials but did not include other study methods/ designs or studies that used mixed methods or qualitative exploratory approaches. This limits the comprehensiveness and depth of the understanding of the process, 
the perceived benefits and different clinical outcomes of CBT on the personal recovery of patients with schizophrenia. Lastly, the review only included experimental studies published in peer-reviewed journals using English language. This could limit the generalisability and validity of the findings of this review.

\section{Implications}

There is insufficient evidence regarding the significant positive long-term effects of CBT on personal recovery outcomes among people with schizophrenia, and more experimental trials with high power are needed in the future. In our study, the QoL and CHIME recovery models were combined to represent personal recovery. However, there are numerous specialised scales designed to measure personal recovery among patients with schizophrenia, and future studies should take these scales into consideration as personal recovery measurement tools. ${ }^{13}$ Other important questions for both research and clinical applications that must be investigated include how long the effect of CBT can be sustained and how to ensure that patients with schizophrenia receive the greatest benefit from CBT intervention in the long term.

\section{CONCLUSION}

Our review showed that CBT is a reasonably effective treatment for some aspects of personal recovery amo to patients with schizophrenia. Our findings reveal improvements in QoL, hope, self-esteem, selfand social connections after CBT intervent $\mathrm{As}$; ho ever, the effect was relatively immediate and $\mathrm{r}$ dly de nosed over time. Therefore, in the future, $\mathrm{a}$ re s s shoura focus on the mechanism of CBT person recovery and the factors that influence e g-term e cts of CBT.

Acknowledgements We thank $L$ American Journal Experts for edití Hyman $>$ Kimberly Yasutis, PhD, from draft 9 is manuscript.

Contributors WW and ZY dorianed the dy and co" suted substantially to the design of the search stra y. data. DL performed th analysis a interpretu data. WW wrote the first draft of the manuscript ar " $z$ critic? approved the final ma

Funding This work was su, red by the National Natural Science Foundation of China (Grant No: 71673070).

Disclaimer The sponsor had no role in the study design, writing of the manuscript, or decision to submit this or future manuscripts for publication.

Competing interests None declared.

Patient consent for publication Not required.

Provenance and peer review Not commissioned; externally peer reviewed.

Data availability statement All data generated or analysed during this study are included in this article.

Open access This is an open access article distributed in accordance with the Creative Commons Attribution Non Commercial (CC BY-NC 4.0) license, which permits others to distribute, remix, adapt, build upon this work non-commercially, and license their derivative works on different terms, provided the original work is properly cited, appropriate credit is given, any changes made indicated, and the use is non-commercial. See: http://creativecommons.org/licenses/by-nc/4.0/.
REFERENCES

1 World Health Organization. Fact sheet about schizophrenia in media center. Genewa: World Health Organization, 2018.

2 Vos T, Barber RM, Bell B, et al. Global, regional, and national incidence, prevalence, and years lived with disability for 301 acute and chronic diseases and injuries in 188 countries, 1990-2013: a systematic analysis for the global burden of disease study 2013. Lancet 2015;386:743-800.

3 Saxena S, Funk M, Chisholm D. World health assembly adopts comprehensive mental health action plan 2013-2020. Lancet 2013;381:1970-1.

4 Health NCCFM. Schizophrenia: core interventions in the treatment and management of schizophrenia in primary and secondary care (update. Social Science Electronic Publishing, 2009.

5 National Institute for Health and Care Excellence. Psychosis and schizophrenia in adults: prevention and management, 2014. Available: https://www.nice.org.uk/guidance/cg178

6 Zimmermann G, Favrod J, Trieu VH, et al. The effect of cognitive behavioral treatment on the positive oms of schizophrenia spectrum disorders: a meta-analy Sch/ or Res 2005;77:1-9.

7 Klingberg S, Wölwer W, Engel et al. Negat symptoms of schizophrenia as primary targe $f$ cognitive be vioral therapy: results of the randomized linical ves study. \& hizophr Bull 2011;37(suppl 2):S98-

$8 \mathrm{YH} \mathrm{M}$. The effects of gnitive hehavi a ap therapy improving social cognition or se self $e^{f}$ acy, rela ship function and social skills for chronic sc oph ra. J Korean Acad Psychiatr Ment Health Nurs 2017;2

9 Gumley A Grady M, nay L al. Early intervention for relapse in schiz ra: results on randomized controlled trial of cogni e beho ural therapy. Ssychol Med 2003;33:419-31.

10 Bateman K, Han L, Turkington D, et al. Cognitive behavioral $y$ reduces su. Jal ideation in schizophrenia: results rom a randomized cortrolled trial. Suicide Life Threat Behav 2007;37:284-90.

Bellack AS. cientific and consumer models of recovery in schizophrer : concordance, contrasts, and implications. Schizophr ull 2006:? 432-42.

12 mering M, Oades L. Recovery: an international perspective. Epidemiol Psichiatr Soc 2008;17:128-37.

RE, Burger TJ, Vellinga A, et al. The relationship between clinical and personal recovery in patients with schizophrenia spectrum disorders: a systematic review and meta-analysis. Schizophr Bull 2017.

14 Mead S, Copeland ME. What recovery means to us: consumers' perspectives. Community Ment Health J 2000;36:315-28.

15 MikeSlade. Personal recovery and mental illness. Cambridge: Cambridge University Press, 2009.

16 Anthony WA. Recovery from mental illness: the guiding vision of the mental health service system in the 1990s. J Psychosoc Rehabil Ment Health 1993;16:11-23.

17 Andresen R, Oades L, Caputi P. The experience of recovery from schizophrenia: towards an empirically validated stage model. Aust $N$ Z J Psychiatry 2003;37:586-94.

18 Leamy M, Bird V, Boutillier CL, et al. Conceptual framework for personal recovery in mental health: systematic review and narrative synthesis. Br J Psychiatry 2011;199:445-52.

19 Rossi A, Amore M, Galderisi S, et al. The complex relationship between self-reported 'personal recovery' and clinical recovery in schizophrenia. Schizophr Res 2017.

20 Davidson L. Living outside mental illness: qualitative studies of recovery in schizophrenia. New York: New York University Press, 2003.

21 Jaeger M, Konrad A, Rueegg S, et al. Patients' subjective perspective on recovery orientation on an acute psychiatric unit. Nord J Psychiatry 2015;69:188-95.

22 Jerrell JM, Cousins VC, Roberts KM. Psychometrics of the recovery process inventory. J Behav Health Serv Res 2006;33:464-73.

23 Resnick SG, Rosenheck RA, Lehman AF. An exploratory analysis of correlates of recovery. PS 2004;55:540-7.

24 Corrigan PW, Salzer M, Ralph RO, et al. Examining the factor structure of the recovery assessment scale. Schizophr Bull 2004;30:1035-41.

25 World Health Organization. Promoting recovery in mental health and related services: handbook for personal use and teaching - WHO QualityRights training to act, unite and empower for mental health (pilot version); (WHO/MSD/MHP/17.11). Geneva: World Health Organization, 2017.

26 Alessandrini M, Lançon C, Fond G, et al. A structural equation modelling approach to explore the determinants of quality of life in schizophrenia. Schizophr Res 2016;171:27-34. 
27 Oles SK, Fukui S, Rand KL, et al. The relationship between hope and patient activation in consumers with schizophrenia: results from longitudinal analyses. Psychiatry Res 2015;228:272-6.

28 Jahn DR, DeVylder JE, Drapalski AL, et al. Personal recovery as a protective factor against suicide ideation in individuals with schizophrenia. J Nerv Ment Dis 2016;204:827-31.

29 Hofmann SG, Asnaani A, Vonk IJJ, et al. The efficacy of cognitive behavioral therapy: a review of meta-analyses. Cognit Ther Res 2012;36:427-40

30 Turner DT, van der Gaag M, Karyotaki E, et al. Psychological interventions for psychosis: a meta-analysis of comparative outcome studies. Am J Psychiatry 2014;171:523-38.

31 Moher D, Liberati A, Tetzlaff J, et al. Preferred reporting items for systematic reviews and meta-analyses: the PRISMA statement. PLoS ONE 2009;18:e123.

32 Higgins JPT, Green S. Cochrane Handbook for systematic reviews of interventions version 5.1.0. The Cochrane collaboration, 2011. Available: http://training.cochrane.org/handbook

33 de Paiva Barretto EM, Kayo M, Avrichir BS, et al. A preliminary controlled trial of cognitive behavioral therapy in clozapine-resistant schizophrenia. J Nerv Ment Dis 2009;197:865-8.

34 Barrowclough C, Haddock G, Lobban F, et al. Group cognitivebehavioural therapy for schizophrenia: randomised controlled trial. $\mathrm{Br}$ J Psychiatry 2006;189:527-32.

35 Bechdolf A, Knost B, Nelson B, et al. Randomized comparison of group cognitive behaviour therapy and group psychoeducation in acute patients with schizophrenia: effects on subjective quality of life. Aust N Z J Psychiatry 2010;44:144-50.

36 Birchwood M, Michail M, Meaden A, et al. Cognitive behaviour therapy to prevent harmful compliance with command hallucinations (command): a randomised controlled trial. Lancet Psychiatry 2014:1:23-33.

37 Edwards J, Cocks J, Burnett P, et al. Randomized controlled trial of clozapine and CBT for First-Episode psychosis with enduring positive symptoms: a pilot study. Schizophr Res Treatment 2011;2011:1-8.

38 Freeman D, Dunn G, Startup H, et al. Effects of cognitive behaviour therapy for worry on persecutory delusions in patients with psychosis (wit): a parallel, single-blind, randomised controlled tr with a mediation analysis. Lancet Psychiatry 2015;2:305-13.

39 Freeman D, Pugh K, Dunn G, et al. An early phase II randomised controlled trial testing the effect on persecutory delusions of using CBT to reduce negative cognitions about the self potential benefits of enhancing self confidence. Schi $\mathrm{hr}_{\mathrm{h}}$ 2014;160:186-92.

40 van der Gaag M, Stant AD, Wolters KJK, et al. therapy for persistent and recurrent psychos schizophrenia-spectrum disorder: cost-effe weness vysis. $\mathrm{BrJ}$ Psychiatry 2011;198:59-65.

41 Garety PA, Kuipers L, Fowler D, et al gh behavioura herapy for drug-resistant psychosis. Br J Med Psycho 994;67:259-71.

42 Gumley A, Karatzias A, Power K al. Early inte ntion for relapse in schizophrenia: impact of $\mathrm{co}$, tive behavioural th apy on negative beliefs about psyg' sis and 'If-esteem. Br J Clin Psychol 2006;45:247-60.

43 Halperin S, Nathan P, Drum, nd al. A ynitive-behavioural, group-based intery an for s anxiety schizophrenia. Aust $N$ Z J Psychiatry 20
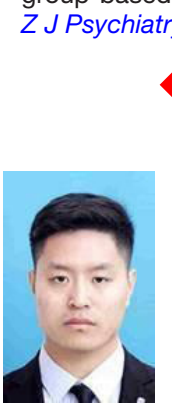

Wet. ng Wang graduated from Xinxiang Medical University of Henan province in 2016. Since 2016, he has been working on successive postgraduate and doctoral programs for Ph.D degree in Harbin Medical University, School of nursing. His research team is currently investigating how to slow down and prevent schizophrenia disability and maintain its social function. In recent years, attention has been paid to the treatment, clinical outcomes and rehabilitation of patients with schizophrenia. They are very interested in the personal recovery of mental illness, the development of clinical assessment tools, and the trajectories of disease development and its relationship with clinical outcomes, brain function and event-related potential studies. His research interest includes mental illness and psychotherapy.
44 Klingberg S, Wittorf A, Fischer A, et al. Evaluation of a cognitive behaviourally oriented service for relapse prevention in schizophrenia. Acta Psychiatr Scand 2010;121:340-50.

45 Kuipers E, Garety P, Fowler D, et al. London-East Anglia randomised controlled trial of cognitive-behavioural therapy for psychosis I: effects of the treatment phase. $\mathrm{Br} J$ Psychiatry 1997;171:319-27.

46 Lysaker PH, Bond G, Davis LW, et al. Enhanced cognitive-behavioral therapy for vocational rehabilitation in schizophrenia: effects on hope and work. JRRD 2005;42:673-82.

47 Mortan O, Tekinsav Sutcu S, German Kose G. A pilot study on the effectiveness of a group-based cognitive-behavioral therapy program for coping with auditory hallucinations. Turk Psikiyatri Derg 2011;22:26-34.

48 Penn DL, Meyer PS, Evans E, et al. A randomized controlled trial of group cognitive-behavioral therapy vs. enhanced supportive therapy for auditory hallucinations. Schizophr Res 2009;109:52-9.

49 Premkumar P, Peters ER, Fannon D, et al. Coping styles predict responsiveness to cognitive behaviour therapy in psychosis. Psychiatry Res 2011;187:354-62

50 Shawyer F, Farhall J, Mackinnor , et al. A rà omised controlled trial of acceptance-based cog ve behaviouro herapy for command hallucinations in psyo tic disorders Behav Res Ther 2012;50:110-21.

51 Steel C, Hardy A, Sm B, et al. Cog e-b aviour therapy for post-traumatic stre in schiz irenia. domized controlled trial. Psychol Med 201 ₹:43-5

52 Wykes T, Hay rd P, as N, et $a$ What are the effects of group cognitive by aviour the vor vo a randomised control trial. Schizopt \$ 2005;77:2

53 Morric AP, w H, Carter (al. Antipsychotic drugs versus cognitve behav ral therapy versus a combination of both in people with nsychosis: a domised controlled pilot and feasibility study. ne rancet. Psychia 2018:5:411-23.

Morrison AP, Pyle M, Gumley A, et al. Cognitive behavioural therapy in clozapin esistant schizophrenia (focus): an assessor-blinded, randomised ontrolled trial. The Lancet. Psychiatry 2018;5:633-43. Pot-Kolder Geraets CNW, Veling W, et al. Virtual-reality-based unitive havioural therapy versus waiting list control for paranoid ideatuvir and social avoidance in patients with psychotic disorders:

56 Tsiachristas A, Waite F, Freeman D, et al. Cost-Effectiveness of cognitive-behavioural therapy for sleep disorder added to usual corizentia: the best study. BJPsych Open 2018;4:126-35.

57 Wood L, Byrne R, Enache G, et al. A brief cognitive therapy intervention for internalised stigma in acute inpatients who experience psychosis: a feasibility randomised controlled trial. Psychiatry Res 2018;262:303-10.

58 Castelein S, van der Gaag M, Bruggeman R, et al. Measuring Empowerment among people with psychotic disorders: a comparison of three instruments. PS 2008;59:1338-42.

59 Choe K. Development and preliminary testing of the schizophrenia hope scale, a brief scale to measure hope in people with schizophrenia. Int J Nurs Stud 2014;51:927-33.

60 Borenstein M, Hedges LV, Higgins JPT, et al. Introduction to metaanalysis. Chichester, England: Wiley, 2009. single-blind randomised controlled trial. The Lancet. Psychiatry 
Retraction: Cognitive-behavioural therapy for personal recovery of patients with schizophrenia: a systematic review and meta-analysis

Wang W, Zhou Y, Chai N, et al. Cognitive-behavioural therapy for personal recovery of patients with schizophrenia: a systematic review and meta-analysis. Gen Psychiatr 2019;32:e100040. doi: 10.1136/gpsych-2018-100040.

This paper has been retracted after errors were found in the original data of the study that affect the main result of the paper. The authors are going to check and renew all the processes of the screening and data collection. Therefore, we are in agreement with the author that this paper should be retracted pending further analysis

\section{(2) \\ OPEN ACCESS}

Open access This is an open access article distributed in accordance with the Creative Commons Attribution Non Commercial (CC BY-NC 4.0) license, which permits others to distribute, remix, adapt, build upon this work non-commercially, and license their derivative works on different terms, provided the original work is properly cited, appropriate credit is given, any changes made indicated, and the use is non-commercial. See: http://creativecommons.org/licenses/by-nc/4.0/.

(C) Author(s) (or their employer(s)) 2019. Re-use permitted under CC BY-NC. No commercial re-use. See rights and permissions. Published by BMJ.

General Psychiatry 2019;32:e100040ret. doi:10.1136/gpsych-2018-100040ret

A) Check for updates 